\title{
Statistical assessment of vegetation dynamics within protected areas using remote sensing data
}

\author{
Maria Elena Menconi, David Grohmann \\ Dipartimento Uomo e Territorio, Università di Perugia, Italy
}

\begin{abstract}
This study aimed to test the effectiveness of protected areas to preserve vegetation. The first step was to identify vegetation suitable areas, designed as areas with optimal morphological terrain features for a good photosynthetic activity. These areas were defined according to the following landscape factors: slope, altitude, aspect and land use. Enhanced vegetation index (EVI) was chosen as vegetation dynamics indicator. This method is based on a statistical approach using remote sensing data in a geographic information system (GIS) environment. The correlation between EVI and landscape factor was evaluated using the frequency ratio method. Classes of landscape factors that show good correlation with a high EVI were combined to obtain vegetation suitable areas. Once identified, these areas and their vegetation dynamics were analysed by comparing the results obtained whenever these areas are included or not included in protected areas. A second EVI dataset was used to verify the accuracy in identifying vegetation suitable areas and the influence of each landscape factor considered in their identification. This validation process showed that vegetation suitable areas are significant in identifying areas with good photosynthetic activity. The effects analysis showed a positive influence of all landscape factors in determining suitability. This methodology, applied to central regions of Italy, shows that the vegetation suitable areas located inside protected areas are greener than those outside protected areas. This suggests that the protective measures established by the institution of the parks have proved to be effective, at least as far as the status of vegetation development is concerned.
\end{abstract}

Correspondence: Maria Elena Menconi, Dipartimento Uomo e Territorio, Università di Perugia, Borgo XX Giugno 74, 06100 Perugia, Italy.

Tel. +39.075.5856024 - Fax: +39.075.5856086.

E-mail: mariaelena.menconi@unipg.it

Key words: areas suitable for vegetation, enhanced vegetation index, frequency ratio, open access data, geographic information system.

Received for publication: 28 January 2013.

Accepted for publication: 20 March 2013.

(C) Copyright M.E. Menconi and D. Grohmann, 2013

Licensee PAGEPress, Italy

Journal of Agricultural Engineering 2013; XLIV:e5

doi:10.4081/jae.2013.e5

This article is distributed under the terms of the Creative Commons Attribution Noncommercial License (by-nc 3.0) which permits any noncommercial use, distribution, and reproduction in any medium, provided the original author(s) and source are credited.

\section{Introduction}

Recently (United Nations, 1992; European Commission 1992; Council of Europe, 2000), when it comes to biodiversity and habitat protection, we generally refer to the concept of ecological network and its modalities of detection, protection and development (Fath et al., 2007; Scotti et al., 2007; Bazelet and Samways, 2011). The traditional forms of protected areas (PA) usually play a fundamental role inside the ecological network (Thompson et al., 2007; Goetz et al., 2009) and their long-established presence allows us to evaluate the degree of protection they have provided (Kharouba and Kerr, 2010; Ioja et al., 2010; Marcer et al., 2010).

The importance of monitoring PA has been confirmed internationally by the Convention on Biological Diversity's Programme of Work on PA in which each country was asked to conduct management effectiveness evaluations on at least $30 \%$ of its PA by 2010 (decision VI/26; Secretariat of the Convention on Biological Diversity, 2005). These studies have often shown the limitations of aesthetic and socio-economic criteria that have contributed to their determination (Scott $e t$ al., 2001; Oldfield et al., 2004), of the zoning and protective measures implemented (Sabatini et al., 2007; Geneletti and Van Duren, 2008; Liu and $\mathrm{Li}, 2008$ ), and the ever-growing influence of the surrounding urbanised areas (McDonald et al., 2009; Borgstrom et al., 2012). Despite these problems, PAs continue to play a key role in biodiversity conservation and it is imperative to verify their effectiveness.

Numerous methodologies and indicators have been developed to do this (Bertzky and Stoll-Kleemann, 2009; Stoll-Kleemann, 2010). In cases of terrestrial PA, the dynamics of vegetation are an important aspect in assessing the health of an environment (Saunders et al., 1998).

Regional-scale studies of vegetation characteristics are typically carried out using remote sensing data (Trodd and Dougill, 1998; Caouette and DeGayner, 2005; Zerger et al., 2009). Remote sensing spectral vegetation indexes are widely used in the assessment of biomass, water use, plant health and crop production. The launch of satellite platform Terra in 1999, with moderate resolution imaging spectroradiometer (MODIS) instrumentation on board, provided freely downloadable data from the data centre of the National Aeronautics and Space Administration (NASA), with excellent temporal and spatial resolutions (Reeves et al., 2001; Li and Fox, 2012).

The purpose of this study is to produce a versatile and low-cost model for large-scale spatial data analysis that can rapidly identify vegetation suitable areas from the point of view of morphological terrain features (VSAM). Therefore, VSAM are areas with optimal morphological terrain features for a good photosynthetic activity. The VSAM have been identified using a frequency ratio method. Although frequency ratio is one of the simplest and easiest statistical methods, it offers a level of accuracy comparable to more complex approaches, such as analytical hierarchy process, logistical regression analysis, and artificial neural network approaches (Pradhan and Lee, 2010; Park et al., 2011). In addition, frequency ratio has already been used successfully 
in other studies to identify susceptible/suitable areas (Lee and Talib, 2005; Park et al., 2011).

The VSAM have been used to assess PA effectiveness on vegetation protection by comparing the results between vegetation performances in VSAM inside PA and in those outside PA. This paper represents a first screening of the suitability of an area for vegetation development, from the point of view of morphological terrain features. Inside the VSAM, the analysis should be focussed on other factors related with vegetation to obtain an exhaustive indication of vegetation suitable areas. The identification of these areas may also help decision-making regarding changes to the boundaries of existing PA and their expansion.

\section{Materials and methods}

To develop the geographic information system (GIS) database, all spatial data have been projected to the WGS84 UTM zone 33N co-ordinates system. The resolution chosen for this work is $250 \times 250 \mathrm{~m}$ as this is the resolution of the less detailed data used (MODIS data).

\section{Study area}

The study area has the following characteristics: i) a size that can be represented by a statistically significant number of pixels (Lee and Talib, 2005) using MODIS Terra imagery, i.e. $250 \times 250 \mathrm{~m}$; ii) characteristics that are similar from a climatic, socio-economic and historical viewpoint so as to reduce the influence of these factors in the interpretation of changes in vegetation dynamics.

The developed method has been applied to regions in central Italy. These regions form a well-defined territorial context $\left(41^{\circ} 12^{\prime} \mathrm{N}, 44^{\circ} 28^{\prime} \mathrm{N}\right.$ latitude, $9^{\circ} 30^{\prime} \mathrm{E}, 14^{\circ} 47^{\prime} \mathrm{E}$ longitude) covering a total area of $70,000 \mathrm{~km}^{2}$ distributed as shown in Table 1.

\section{Choice of vegetation index}

In satellite remote sensing applications, the most common vegetation indexes are of an intrinsic nature that analyse the activity of vegetation based only on measured spectral reflectance. These include: ratio vegetation index (Jordan, 1969) and the normalised difference vegetation index (Rouse et al., 1974). More recently, Liu and Huete (1995) have proposed a vegetation index called enhanced vegetation index (EVI). The EVI is able to detect the response of vegetation through a de-coupling of canopy background signal and a reduction in atmospheric influences (Huete et al., 2002; Napolitano et al., 2005) according to the equation:

$$
E V I=G *\left(\frac{\left(\rho_{n i r}-\rho_{r}\right)}{\left(L+\rho_{n i r}+C_{1} * \rho_{r}-C_{2} * \rho_{b}\right)}\right)
$$

where

$\mathbf{G}$ is the gain factor, $r_{n i r}, r_{r}, r_{b}$ are the surface reflectances of nearinfrared, red and blue bands, $\mathrm{L}$ is the canopy background adjustment that addresses non-linear differential NIR and red radiant transfer through a canopy, $\mathrm{C}_{1}$ and $\mathrm{C}_{2}$ are the co-efficients of the aerosol resistance term which uses the blue band to correct for aerosol influences in the red band.

In this study, we chose to use the EVI (MOD 13 data products) detected by the MODIS sensor aboard the Terra satellite (freely downloadable at: http://modis.gsfc.nasa.gov).

The files are segmented into tiles with an area of $10^{\circ} \times 10^{\circ}$ and contain information relating to 12 different bands.

EVI measures the amount of green biomass and occupies one band of the following product: MODIS/Terra Vegetation Indices 16-Day L3
Global 250m SIN grid V005; one of the available spatial resolution is 250 $\mathrm{m}$ and the temporal resolution is 16 days. EVI values are calculated using the maximum values for a period of 16 days (maximum composite value) in order to compensate for the possible presence of null values caused by the persistence of cloud formations on the areas of recovery. Several studies have shown that EVI is strongly linked to many ecosystem variables such as leaf area index, biomass, canopy cover and fraction of absorbed photosynthetically active radiation (Huete et al., 2002; Portillo-Quintero et al., 2012). EVI is characterised by a theoretical range of linear values between -1 and 1 ; for bare soil it assumes values slightly above zero, reaching higher values the denser the vegetation (Huete et al., 2002).

A total of 48 data containing EVI band for 2010 were downloaded from the NASA website; for 2010 , for each granule 24 files are available, and 2 granules are needed to cover the entire spatial extent of analysis for the study area. The EVI performance trend analysis on these data showed that the period of most intense vegetation vigour for the study area in 2010 is between $10^{\text {th }}$ and $25^{\text {th }}$ June. This period was, therefore, chosen for study.

EVI values were grouped into 4 classes of variability where class 1 (EVI1) represents low photosynthetic activity and class 4 (EVI4) high photosynthetic activity.

\section{Choice of landscape factors}

There are many and important factors related to vegetation dynamics: vegetation types, morphological terrain features (e.g. altitude, aspect, slope), climate (precipitation, wind), hydrological profile (distance from river, groundwater depth), ground condition (soil type, soil drainage). Since this study is a first screening of the suitability of an area for vegetation development, and to ensure simplicity and cost-free data acquisition, it was decided to use standard sets available nationally, such as the Corine Land Cover (CLC) and the Digital Terrain Model (DTM), from which to derive altitude ranges, aspect and slope.

CLC 2006 (version 13 February 2010, raster data. Freely available from: http://www.eea.europa.eu/data-and-maps/data/corine-land-cover2006-raster) is used for covering land use. The classification used in this study for land use is the third level of CLC which includes 44 different types of land use. In the study area, the following 4 land cover types are not present: glacier and perpetual snow, peat bog, intertidal flats, estuaries, so the number of classes used in the subsequent statistical analysis has been reduced to 40 .

The DTM data source used in this analysis is the Web Map Service provided by the Italian National Cartographic Portal (available from: http://www.pcn.minambiente.it/PCNDYN/catalogowms.jsp?Ian=it).

A product with a resolution of $75 \times 75 \mathrm{~m}$ was downloaded and was then re-sampled to the work resolution. Starting from the DTM, slope and aspect of the study area can easily be obtained using a common GIS tool. The study area was then split into 8 elevation classes: lowland (0$200 \mathrm{~m}$ asl), low hills (200-400 $\mathrm{m}$ asl), hill (400-600 m asl), high hills

Table 1. Study area: size and location (data source: http://www.istat.it).

\begin{tabular}{|c|c|c|c|}
\hline Region & & Area $\left(\mathrm{km}^{2}\right)$ & Area (\%) \\
\hline Abruzzi & & $10,789.50$ & 33.28 \\
\hline Latium & & $17,200.21$ & 12.22 \\
\hline Marches & & 9708.23 & 14.03 \\
\hline Tuscany & & $23,021.09$ & 24.87 \\
\hline \multirow[t]{2}{*}{ Umbria } & & 8455.85 & 15.60 \\
\hline & Study area & $69,174.88$ & 100 \\
\hline
\end{tabular}


(600-800 m asl), low mountains (800-1000 m asl), mountains (1000$1500 \mathrm{~m}$ asl), medium-high mountains (1500-2000 m asl), high mountains (above $2000 \mathrm{~m}$ asl), 7 homogeneous slope classes with steps of $5^{\circ}$, and 9 aspect classes.

\section{Relationship between enhanced vegetation index and the degree of correlation between two georeferenced variables: frequency ratio method}

Frequency ratio is a simple statistical method that evaluates the degree of correlation between two georeferenced variables (EVI-LF). The EVI is a response variable in relation to a set of state variables representative of the area analysed: land use, altitude, slope, aspect. A statistical analysis approach is appropriate when it is assumed that those physical and morphological characteristics of the study area that have EVI higher values (EVIhv: EVI class 3 and 4) will allow EVIhv to be maintained in the future as well. The correlation between EVI variability and classes of land use has been analysed in different contexts (Zerger et al., 2006; Mondal, 2011) and has always been significant, whereas for the relationship between EVI and topographic characteristics of soil, the research has shown that it is correct to analyse this on a planning scale, but not at spatial resolutions of great detail, because this index is influenced by the roughness of terrain (Matsushita et al., 2007). The frequency ratio calculations are shown in Table 2 where $x_{i}$ indicates the $\mathrm{EVI}_{\mathrm{i}}$ class and $\mathrm{y}_{\mathrm{kj}}$ the class $j$ of the $\mathrm{LF} k$. The counter variable $i$ assumes values from 1 to $\mathrm{I}$, where I is the number of EVI classes, the counter variable $j$ from 1 to $\mathrm{J}$, where $\mathrm{J}$ is the number, variable for each LF, of the classes in which the values are grouped. Finally, the variable counter $k$ assumes values from 1 to $\mathrm{K}$, where $\mathrm{K}$ is the number of LF analysed. $X_{i}$, is the total number of cells of the study area falling in $\mathrm{i}^{\text {th }}$ class of EVI and $\mathrm{Y}$ is the total number of cells analysed:

$$
Y=\Sigma_{i} X_{i}
$$

The total number of frequency ratios calculated is given by the total number of classes into which the LF are divided, multiplied by the number of EVI classes (I), as shown in Eq. (3).

$$
n . F R=\Sigma_{k} j * I
$$

In the present study, the counter variables assume the following values: $\mathrm{I}=4$ and $\mathrm{K}=4$; for $k$ equal to 1 (CLC) $\mathrm{J}$ assumes the value of 40 ; for $k$ equal to 2 (altitude) $\mathrm{J}$ assumes the value of 8 ; for $k$ equal to 3 (slope) $\mathrm{J}$ assumes the value of 7 ; for $k$ equal to 4 (aspect) $\mathrm{J}$ assumes the value of 9 . According to Eq. (3), the total number of frequency ratios is 256 .

\section{View of morphological terrain features and protected areas}

Classes of LF that show a good correlation with high EVI are combined to obtain VSAM according to Eq. (4):

$$
V S A M=\bigcap_{i k j}(p * F R)
$$

where the variable frequency ratio is the correlation value of the $i^{\text {th }}$ class of EVI and the $j^{\text {th }}$ class of $k$-th LF and $p$ represents the weight assigned to every frequency ratio calculated; $p$ assumes value 1 with a frequency ratio greater or equal to unity, 0 in all other cases.

VSAM were then classified as internal and external to PA, and EVI performances in the two classes were compared. It has been decided to apply this methodology only to those PA classified as parks, since these are the areas with the most significant extensions. Parks cover approximately $10 \%$ of the whole national territory and are approximately $90 \%$ of all the terrestrial protected areas nationally (Table 3 ). In addition, parks are particularly important to monitor because their historic institution has meant that financial resources will continue to be allocated for their conservation.

\section{Results}

\section{Data analysis}

In the study area, EVI values mostly fall within two intermediate classes (class 2 and 3) (Table 4); EVIhv mostly correspond to the Apennine ridge (Figure 1).

As far as land use is concerned, the most representative classes are Broad-leaved forest (code 311, 28.5\%) and non-irrigated arable land (code $211,27 \%$ ), which together cover more than $50 \%$ of the total surface.

From a morphological standpoint, the Apennine ridge that crosses central Italy from north to south has a relatively low average altitude, as mountain areas ( $>1000 \mathrm{~m}$ asl) cover approximately $10 \%$ of the study area and the most represented class is lowland (approx. 30\%). The slopes are gentle (approx. $75 \%<15^{\circ}$, approx. $25 \%<5^{\circ}$ ) except in some areas of the Apennines. Exposures are evenly distributed; flat areas are less than $1 \%$.

In the study area, there are 8 National Parks and 30 Regional Parks, altogether covering $9.36 \%$ of the total area, slightly below the national average (Figure 2).

The most recent park was established in 1999 (Parco Naturale Regionale di Bracciano), while the oldest were established by Royal Decree in 1923 (Parco Nazionale dell'Abruzzo, Lazio e Molise; Parco Nazionale del Gran Sasso e Monti della Laga).

\begin{tabular}{|c|c|c|c|c|c|}
\hline & n. $x_{i}$ & $\mathbf{A}$ & $n . y_{k j}$ & B & $\mathrm{FR}_{\mathrm{ikj}}$ \\
\hline$y_{k j}$ & $\begin{array}{l}\text { No. of events } \\
\text { ith EVI class } \\
\text { falling into jth } \\
\text { class of kth LF }\end{array}$ & $\begin{array}{l}\text { Percentage } \\
\text { of } \mathrm{x}_{\mathrm{i}} \text { events } \\
\text { falling into } \mathrm{y}_{\mathrm{kj}} \\
\left(\mathrm{n} . \mathrm{x}_{\mathrm{i}}^{*} 100 / \mathrm{X}_{\mathrm{i}}\right)\end{array}$ & $\begin{array}{l}\text { No. of cells } \\
\text { of study } \\
\text { area falling } \\
\text { into } y_{\mathrm{kj}} \text { class }\end{array}$ & $\begin{array}{l}\text { \% cells falling } \\
\text { into } y_{\mathrm{kj}} \text { class } \\
\left(\mathrm{n} . \mathrm{y}_{\mathrm{kj}} * 100 / \mathrm{Y}\right)\end{array}$ & $\begin{array}{c}\text { Correlation level } \\
\text { between } \mathrm{j}^{\text {th }} \text { class of } \mathrm{i}^{\text {th }} \\
\mathrm{LF}\left(\mathrm{y}_{\mathrm{kj}}\right) \text { and } \mathrm{i}^{\text {th }} \text { EVI class }\left(\mathrm{x}_{\mathrm{i}}\right) \\
\mathrm{FR}_{\mathrm{ikj}}=\mathrm{A} / \mathrm{B}\end{array}$ \\
\hline Total & $X_{\mathrm{i}}$ & - & Y & - & - \\
\hline
\end{tabular}

Table 2. Equation for frequency ratio calculation: enhanced vegetation index classes/degree of correlation between two georeferenced variables classes.

FR, frequency ratio; EVI, enhanced vegetation index; LF, the degree of correlation between two georeferenced variables. 


\section{Relationship between enhanced vegetation index and the degree of correlation between two georeferenced variables: results of frequency ratio method}

Results of frequency ratio method are discussed for every LF; Table 5 shows frequency ratio calculations for class 3 of EVI as an example.

Where frequency ratio is greater than 1 , there is a good correlation between $\mathrm{j}^{\text {th }}$ class of $\mathrm{LF}_{\mathrm{k}}$ and EVI3; in order to avoid statistically not significant results, as performed on a negligible number of pixels, frequency ratio results for those values of $\mathrm{A}$ or $\mathrm{B}$ below 1 were not considered.

\section{Relationship between enhanced vegetation index and Corine Land Cover}

The class with the best correlation with EVI4 is Broad-leaved forest (Corine code 3.1.1). Classes that have a good correlation with the EVI3 are, in descending order, broad-leaved forest (Corine code 3.1.1.), mixed forest (Corine code 3.1.3.), transitional woodland-shrub (Corine code 3.2 .4 .). Land mainly occupied by agriculture with significant areas of natural vegetation (Corine code 2.4.3.), pastures (Corine code 2.3.1.) and natural grassland (Corine code 3.2.1.).

This means that the most vegetative growth occurs for broad-leaved forest and mixed forest, involving $61.24 \%$ of the study area with EVIhv.

\section{Relationship between enhanced vegetation index and morphological terrain features}

As regards morphological terrain features, the elevation classes showing good correlation with EVIhv go from high hills to high mountains, where the forest areas are concentrated. With regard to the slope classes, it seems that they do not have any particular influence on EVI performance, except for extreme values. For very steep slopes, the good correlation is not significant because of the low number of pixels analysed; for flat areas with slopes of less than $5^{\circ}$, the lack of correlation may be due to the fact that these areas are usually characterised by a strong anthropic use (urban areas and intensive agriculture).

With regards to aspect, moving clockwise, a good correlation can be observed of the areas exposed from north-west to north-east with the EVI3 class and from east to south with EVI4. This could be due to the fact that, as the altitude increases, the thermophilic species tend to colonise the warmer slopes.

\section{Effect analysis and validation}

The results of Eq. 4 in the study area show that VSAM cover 18.62\% of the total area and are distributed mainly along the Apennine ridge (Figure 2). An effect analysis has been performed to verify which LF have the greatest effect in determining the VSAM, re-calculating 4 new VSAM, each without one LF. Inside the 5 generated VSAM (VSAM, VSAM except slope, VSAM except aspect, VSAM except altitude, VSAM except CLC) and inside the whole study area, the EVI performance have been analysed with the work data ( $10^{\text {th }}-25^{\text {th }}$ June) (Table 6$)$.

These results were then validated with a second EVI dataset related to the period just preceding that used in the study (May $25^{\text {th }}-10^{\text {th }}$ June: validation value) (Table 7). From the analysis of the trends, it can be observed how in both cases the EVI values tend to be higher inside the VSAM than in the rest of the study area (Tables 6 and 7). CLC, with both study and validation data, is the LF with the greatest influence on EVI variations. This can be observed from the lowering of the mean and median values in the VSAM where Corine classes have been taken into account. The LF with the lowest influence is slope. However, even if only slightly, the values of the mean and median in the VSAM without

Table 3. Distribution of protected areas types on a national level (data source: official list of natural protected areas, $6^{\text {th }}$ update 2010 , Ministerial Decree of 27 April 2010) (Italian Regulation, 2010).

\begin{tabular}{lcccc} 
PA type & No. & Surface (ha) & $\begin{array}{c}\text { Relative frequency } \\
\text { of the surface occupied } \\
\text { by PA }\end{array}$ & $\begin{array}{c}\text { Percentage on national } \\
\text { territory }\end{array}$ \\
National park & 24 & $1,465,681.01$ & 0.46 & 4.86 \\
Marine protected areas & 27 & 0 & 0.00 & 0.00 \\
\hline Nature state reserve & 147 & $122,775.90$ & 0.04 & 0.41 \\
Other national protected areas & 3 & 0 & 0.00 & 0.00 \\
\hline Regional parks & 134 & $1,294,655.87$ & 0.41 & 4.30 \\
Nature regional reserve & 365 & $230,240.21$ & 0.07 & 0.76 \\
\hline Other regional protected areas & 171 & $50,237.72$ & 0.02 & 0.17 \\
Total & 871 & $3,163,590.71$ & 1 & 10.50 \\
\hline
\end{tabular}

PA, protected area.

Table 4. Performance of the 4 classes enhanced vegetation index inside study area.

\begin{tabular}{lccc}
\hline EVI class & EVI variation range & Percentage of the whole study area \\
1 & $0-0.25$ & 61,415 & 4.76 \\
2 & $0.25-0.50$ & 696,944 & 54.07 \\
\hline 3 & $0.50-0.75$ & 517,266 & 40.13 \\
\hline Total & $0.75-1$ & 13,416 & 1.04 \\
\hline
\end{tabular}

EVI, enhanced vegetation index. 
slope are lower than those of the VSAM, so it can be concluded that all the considered LF have a positive influence on VSAM. Therefore, with this methodology, even if there are some LF which are less significant, this would lead, at worst, to missing some of the areas and not identifying false suitability.

\section{Relationship between view of morphological terrain features and protected area within the study area}

Around 35\% of the VSAM are located within PA (Figure 2). The spatial pattern of the EVI were then re-analysed within VSAM, differentiating the results between inside PA and outside PA. Observing the variations in EVI variability, it appears that the areas contained in EVIhv increased from $83.3 \%$ (outside $\mathrm{PA}$ ) to $88.8 \%$ (inside $\mathrm{PA}$ ). This confirms that there is a greater concentration of EVIhv in VSAM that are located within the PA (Table 8). An immediate way to test the strength of the dependence between EVIhv and PA is the Chi-Square $\left(\chi^{2}\right)$ Pearson's test. There are numerous non-parametric frequency validation tests that have found wide application, like the Kolmogorov-Smirnov test (Smirnov, 1948) and Fisher's exact test (Fisher, 1922), but it was decided to proceed using the Pearson's $\chi^{2}$ test (Plackett, 1983) for the nominal nature of the variables involved and for its reliability even in the presence of a limited number of samples (Greenwood, 1996). The result is $\chi^{2}=779.36$, with odds ratio of 1.59. These values show a good association between EVIhv and PA.

\section{Discussion and conclusions}

The study has developed an easily reproducible, inexpensive method (using only freely downloadable georeferenced data) for rapid identification of VSAM. The effect analysis has shown that all the LF considered have a positive influence on determining such vegetation suitable areas, also validated using EVI data from a different period (May). An interesting development could be to use, inside VSAM, other suitability indexes based on the intersection or the weighted sum of other LF in order to grade the assignment of value in the analysed area. As with all studies developed on a regional scale, the VSAM represent those areas where further investigation in greater detail and with other indicators is required. In all cases, VSAM can support decision making by identifying those zones where existing PA should be extended or new ones created. The study showed that there is a good association between EVIhv and PA. Therefore, we can conclude that PA play an active role in protecting vegetation and do not only serve a purely formal function, despite different results obtained outside the European context (Fuller et al., 2010). This hypothesis has contributed to the evaluation of the protective capacity of PA. Where a good monitoring modality has been implemented, it has been possible to identify mistakes and to find the best management strategies (Verburg et al., 2006; McDonald and Boucher, 2011). This result, if inserted in a broader context of the analysis of other vegetation indexes, the monitoring of species, and the

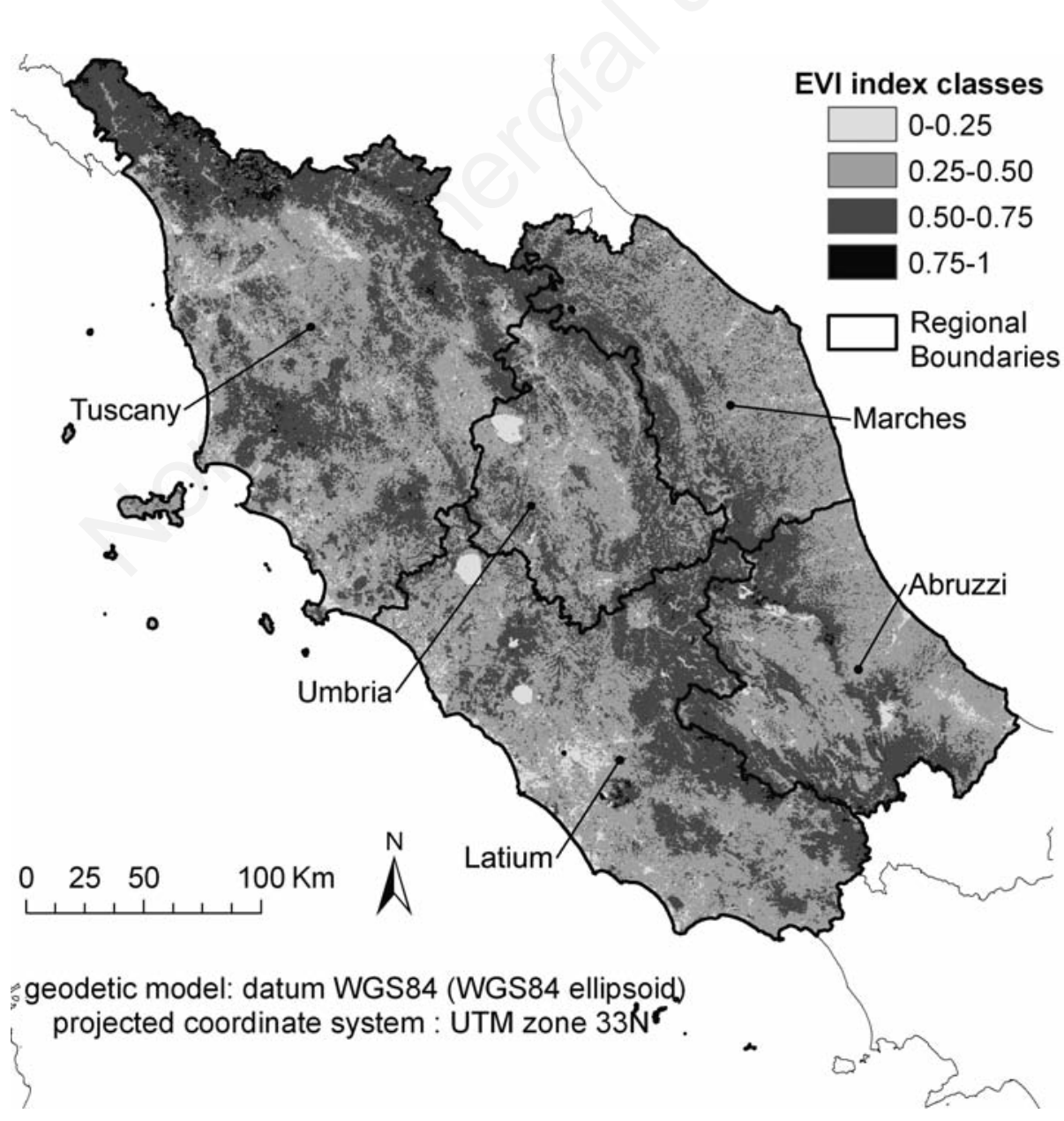

Figure 1. Boundaries of study area with information about enhanced vegetation index (EVI) variability. 
Table 5. Example of frequency ratio calculation table for enhanced vegetation index class 3.

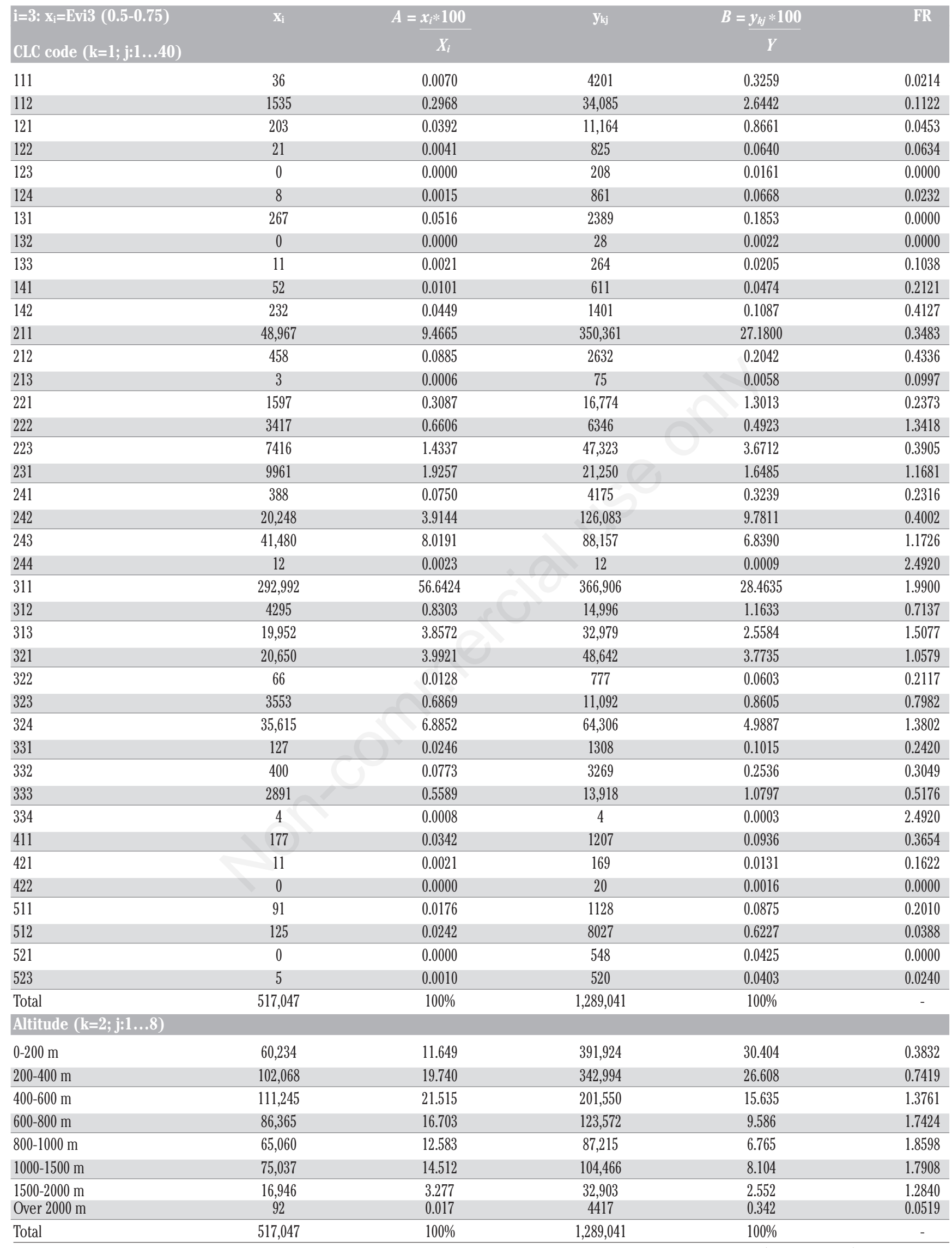


Table 5. Continued from previous page.

\begin{tabular}{|c|c|c|c|c|c|}
\hline$i=3: x_{i}=E v i 3(0.5-0.75)$ & $x_{i}$ & $A=x_{i} * 100$ & $\mathrm{y}_{\mathrm{kj}}$ & $B=\underline{y_{k j} * 100}$ & FR \\
\hline Aspect $(\mathrm{k}=3, \mathrm{j}: 1 \ldots 9)$ & & $X_{i}$ & & $Y$ & \\
\hline Flat & 2017 & 0.390 & 25,511 & 1.979 & 0.1971 \\
\hline North & 59,347 & 11.478 & 68,134 & 5.285 & 2.1716 \\
\hline North east & 73,389 & 14.193 & 159,666 & 12.386 & 1.1459 \\
\hline East & 69,329 & 13.408 & 159,889 & 12.403 & 1.0810 \\
\hline South east & 61,798 & 11.952 & 155,223 & 12.041 & 0.9926 \\
\hline South & 57,985 & 11.214 & 158,148 & 12.268 & 0.9141 \\
\hline South west & 67,921 & 13.136 & 183,641 & 14.246 & 0.9221 \\
\hline West & 66,335 & 12.829 & 170,017 & 13.189 & 0.9727 \\
\hline North west & 58,926 & 11.396 & 142,460 & 11.051 & 1.0312 \\
\hline Total & 517,047 & $100 \%$ & $1,289,041$ & $100 \%$ & - \\
\hline \multicolumn{6}{|l|}{ Slope $(k=4 ; j: 1 \ldots 7)$} \\
\hline $0-5^{\circ}$ & 125,592 & 24.290 & 598,881 & 46.459 & 0.5228 \\
\hline $6-10^{\circ}$ & 155,788 & 30.130 & 334,875 & 25.978 & 1.1598 \\
\hline $11-15^{\circ}$ & 114,416 & 22.128 & 180,029 & 13.966 & 1.5845 \\
\hline $16-20^{\circ}$ & 63,598 & 12.300 & 91,156 & 7.071 & 1.7394 \\
\hline $21-25^{\circ}$ & 34,056 & 6.586 & 48,649 & 3.774 & 1.7452 \\
\hline $26-30^{\circ}$ & 16,270 & 3.146 & 23,780 & 1.844 & 1.7057 \\
\hline Over $30^{\circ}$ & 7327 & 1.417 & 11,671 & 0.905 & 1.5651 \\
\hline Total & 517,047 & $100 \%$ & $1,289,041$ & $100 \%$ & - \\
\hline
\end{tabular}

Evi, enhanced vegetation index; FR, frequency ratio; CLC, Corine Land Cover.

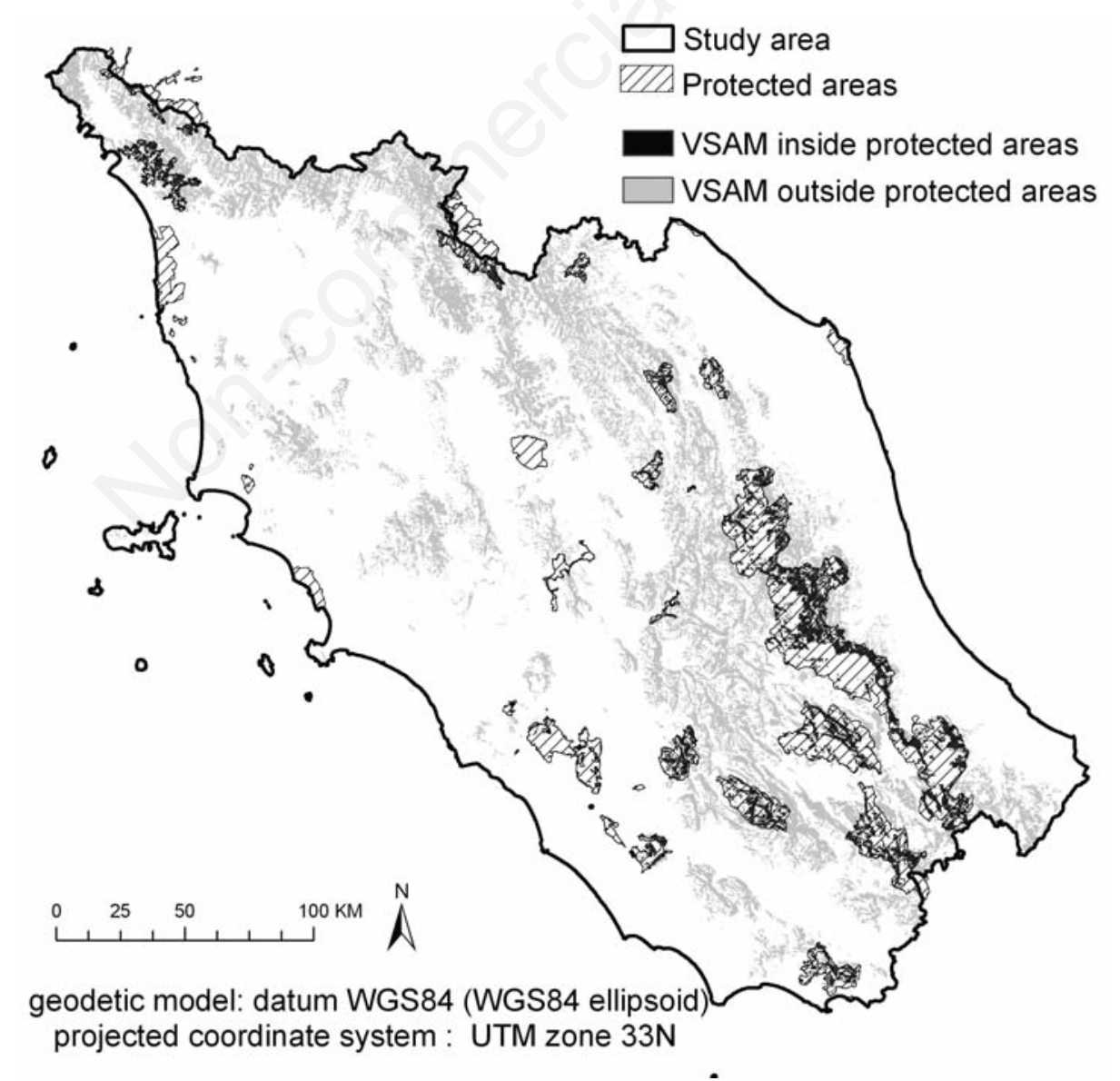

Figure 2. View of morphological terrain features (VSAM) and protected areas identification in the study area. 
Table 6. Statistics concerning enhanced vegetation index (Evi_value) performance in view of morphological terrain features varying the degree of correlation between two georeferenced variables in the two periods: $10^{\text {th }}-25^{\text {th }}$ June and $25^{\text {th }}$ May- $10^{\text {th }}$ June.

\begin{tabular}{lcccccc}
\hline Evi_value & Minimum value & Maximum value & Range & Mean value & Standard deviation & Median \\
VSAM except alt. & 0.00 & 1.00 & 1.00 & 0.5746 & 0.0971 & 0.5759 \\
VSAM except slope & 0.04 & 1.00 & 0.96 & 0.5880 & 0.0937 & 0.0939 \\
\hline VSAM except aspect & 0.00 & 1.00 & 1.00 & 0.5862 & 0.5898 \\
VSAM except corine & 0.00 & 1.00 & 1.00 & 0.5633 & 0.1054 & 0.0930 \\
\hline VSAM & 0.06 & 1.00 & 0.94 & 0.5920 & 0.1310 & 0.5937 \\
Study area & 0.00 & 1.00 & 1.00 & 0.4690 & 0.4690 \\
\hline
\end{tabular}

Evi, enhanced vegetation index; VSAM, view of morphological terrain features; alt., altitude.

Table 7. Statistics concerning enhanced vegetation index (Evi_validation value) performance in view of morphological terrain features varying the degree of correlation between two georeferenced variables in the two periods: $10^{\text {th }}-25^{\text {th }}$ June and $25^{\text {th }}$ May- $10^{\text {th }}$ June.

\begin{tabular}{lcccccc}
\hline Evi_validation value & Minimum value & Maximum value & Range & Mean value & Standard deviation & Median \\
VSAM except alt. & 0.07 & 0.99 & 0.92 & 0.5904 & 0.0886 & 0.5911 \\
VSAM except slope & 0.01 & 0.99 & 0.98 & 0.6015 & 0.0874 & 0.6033 \\
\hline VSAM except aspect & 0.07 & 0.99 & 0.92 & 0.5991 & 0.0881 & 0.6011 \\
VSAM except corine & 0.01 & 0.99 & 0.98 & 0.5785 & 0.1003 & 0.5828 \\
\hline VSAM & 0.07 & 0.99 & 0.92 & 0.6039 & 0.0877 & 0.1211 \\
Study area & 0.00 & 0.99 & 0.99 & 0.5053 & 0.5121 \\
\hline
\end{tabular}

Evi, enhanced vegetation index; VSAM, view of morphological terrain features; alt., altitude.

Table 8. Strength of the correlation between higher values of enhanced vegetation index and protected areas: contingency table.

\begin{tabular}{|c|c|c|c|c|c|c|c|c|}
\hline & \multicolumn{4}{|c|}{ Observed values } & \multicolumn{4}{|c|}{ Expected values } \\
\hline & EVIhv & EVI1_2 & Total & \%EVIhv & EVlhv & EVI1_2 & Total & \%EVIhv \\
\hline Inside PA & 37,276 & 4716 & 41,992 & 88.8 & $35,394.12$ & 6597.88 & 41,992 & 84.3 \\
\hline Outside PA & 156,242 & 31,358 & 187,600 & 83.3 & $158,123.88$ & $29,476.12$ & 187,600 & 84.3 \\
\hline \multirow[t]{2}{*}{ Total } & 193,518 & 36,074 & 229,592 & 84.3 & 193,518 & 36,074 & 229,592 & 84.3 \\
\hline & \multicolumn{3}{|c|}{$\chi^{2}=779.36$} & & \multicolumn{4}{|c|}{ Odds ratio= $=1.59$} \\
\hline
\end{tabular}

EVIhv, higher values of enhanced vegetation index

examination of social and economic factors conditioning the performance of the different PA analysed, would provide in-depth evaluation of the PA and guide optimal PA management (Thackway et al., 2007; Yapp et al., 2010). The parks studied have, over time, finalised heterogeneous measures of protection, both internally and between different parks (Peano and Mausello 1997; Boatti and Papa, 1995). It would be interesting to re-apply the defined methodology by differentiating the results according to the measures implemented (Pressey et al., 1996), to assess which have been the most effective.

The methodology developed is transferable to other contextes, is flexible and can be reproduced using other vegetation indicators and other land factors.

\section{References}

Bazelet C.S., Samways M.J. 2011. Identityng grasshopper biondicators for habitat quality assessment of ecological networks. Ecol. Indic. 11: 1259-69.

Bertzky M., Stoll-Kleemann S. 2009. Multi-level discrepancies with sharing data on protected areas: what we have and what we need for the global village. J. Environ. Manag. 90:8-24.

Boatti A., Papa D. 1995. Parchi e protezione del territorio, realtà e progetti europei, nazionali, regionali [Parks and land protection. Case studies and projects at European, national and regional level]. Franco Angeli, Milano, Italy. [In Italian].
Borgstrom S., Cousins S.A.O., Lindborg R. 2012. Outside the boundary e land use changes in the surroundings of urban nature reserves. Appl. Geogr. 32:350-9.

Caouette J.P., DeGayner E.J. 2005. Predictive mapping for tree sizes and densities in Southeast Alaska. Landscape Urban Plan. 72:49-63.

Council of Europe. 2000. European landscape convention, ETS 176. The Secretary General of the Council of Europe, Florence, Italy. Available from: http://conventions.coe.int/Treaty/en/Treaties/Html/176.htm

European Commission. 1992. Council Directive 92/43/EEC of 21 May 1992 on the conservation of natural habitats and of wild fauna and flora. In: Official Journal, L 206, 22/7/1992, pp 7-50. Available from: http//eurlex.europa.eu/LexUriServ/LexUriServ.do?uri=CELEX:31992L0043:en:NO $\mathrm{T}$

Fath B.D., Scharler U.M., Ulanowicz R.E., Hannon B. 2007. Ecological network analysis: network construction. Ecol. Model. 208:49-55.

Fisher R.A. 1922. On the interpretation of ${ }^{2}$ from contingency tables, and the calculation of P. J. Roy. Stat. Soc. 85:87-94.

Fuller D.0., Meijaard E.M., Christy L., Jessup T.C. 2010, Spatial assessment of threats to biodiversity within East Kalimantan, Indonesia. Appl. Geogr. 30:416-25.

Geneletti D., Van Duren I. 2008. Protected area zoning for conservation and use: A combination of spatial multicriteria and multiobjective evaluation. Landscape Urban Plan. 85:97-110.

Goetz S.J., Jantz P., Jantz C.A. 2009. Connectivity of core habitat in the Northeastern United States: Parks and protected areas in a landscape context. Remote Sens. Environ. 113:1421-9.

Greenwood P.E., Nikulin M.S. 1996. A guide to chi-squared testing. J. 
Wiley, New York, NY, USA

Huete A., Didan K., Miura T., Rodriguez E.P., Gao X., Ferreira L.G. 2002. Overview of the radiometric and biophysical performance of the MODIS vegetation indices. Remote Sens. Environ. 83:195-213.

Ioja C.I., Patroescu M., Rozylowicz L., Popescu V.D., Verghelet M., Zotta M.I., Felciuc M. 2010. The efficacy of Romania's protected areas network in conserving biodiversity. Biol. Conserv. 143:2468-76.

Italian Regulation. 2010. Ministero dell'Ambiente e della tutela del territorio e del mare - Decreto 27 aprile 2010. Approvazione dello schema aggiornato relativo al VI Elenco ufficiale delle aree protette, ai sensi del combinato disposto dell'articolo 3, comma 4, lettera c), della legge 6 dicembre 1994, n. 394 e dall'articolo 7, comma 1, del decreto legislativo 28 agosto 1997, n. 281. In: Official Journal no. 125, S.0. no. 115, $31 / 5 / 2010$.

Jordan C.F. 1969. Derivation of leaf area index from quality of light on the forest floor. Ecology. 50:663-6.

Kharouba H.M., Kerr J.T. 2010. Just passing through: global change and the conservation of biodiversity in protected areas. Biol. Conserv. 142:1094-101.

Lee S., Talib J.A. 2005. Probabilistic landslide susceptibility and factor effect analysis. Environ. Geol. 47:982-90.

Li Z., Fox Jefferson M. 2012. Mapping rubber tree growth in mainland Southeast Asia using time-series MODIS $250 \mathrm{~m}$ NDVI and statistical data. Appl. Geogr. 32:420-32.

Liu H., Huete A.R. 1995. A feedback based modification of the NDVI to minimize canopy background and atmospheric noise. IEEE Trans. Geosci. Remote Sens. 33:457-65.

Liu X., Li J. 2008. Scientific solutions for the functional zoning of nature reserve in China. Ecol. Model. 215:237-46.

Marcer A., Garcia V., Escobar A., Pons X. 2010. Handling historical information on protected-area systems and coverage. An information system for the Natura 2000 European context. Environ. Model. Software. 25:956-64.

Matsushita B., Yang W., Chen J., Onda Y., Qiu G. 2007. Sensitivity of the enchanced vegetation index (EVI) and normalized difference vegetation index (NDVI) to topographic effects: a case study in high-density cypress forest. Sensors. 7:2636-51.

McDonald R.I., Boucher T.M. 2011. Global development and the future of the protected area strategy. Biol. Conserv. 144:383-92.

McDonald R.I., Formann R.T.T., Kareiva P., Neugarten R., Salzer D., Fisher J. 2009. Urban effects, distance, and protected areas in an urbanizing world. Landscape Urban Plan. 93:63-75.

Mondal P. 2011. Quantitying surface gradients with a 2-band enchanced vegetation index (EVI2). Ecol. Indic. 11:918-24.

Napolitano R., Altobelli A., Feoli E., Bressan E. 2005. Stima della biomassa verde in diverse tipologie forestali del friuli Venezia Giulia attraverso il satellite MODIS e misure indirette in campo di LAI [Green biomass estimation in different forest types of the Friuli Venezia Giulia through the satellite MODIS and indirect measurements of LAI in the field] in Proc. $15^{\text {th }}$ meeting of the Italian Society of Ecology, 12-14 settembre, Torino, Italy. Available from: http//www.ecologia.it/congressi/XV/articles/ [In Italian].

Oldfield T.E.E., Smith R.J., Harrop S.R., Leader-Williams N. 2004. A gap analysis of terrestrial protected areas in England and its implications for conservation policy. Biol. Conserv. 120:303-9.

Park S., Jeon S., Kim S., Choi C. 2011. Prediction and comparison of urban growth by land suitability index mapping using GIS and RS in South Korea. Landscape Urban Plan. 99:104-14.

Peano A., Mansuello C. 1997. Politiche e pianificazione nei parchi italiani. INU, Roma, Italy.

Plackett R.L. 1983. Karl Pearson and the Chi-Squared Test. Int. Stat. Rev. 51:59-72.
Portillo-Quintero C.A., Sanchez A.M., Valbuena C.A., Gonzalez Y.Y., Larreal J.T. 2012. Forest cover and deforestation patterns in the Northern Andes (Lake Maracaibo Basin): A synoptic assessment using MODIS and Landsat imagery. Appl. Geogr. 35:152-63.

Pradhan B., Lee S., 2010. Landslide susceptibility assessment and factor effect analysis: backpropagation artificial neural networks and their comparison with frequency ratio and bivariate regression modelling. Environ. Model. Software. 25:747-59.

Pressey R.L., Ferrier S., Hager T.C., Woods C.A., Tully S.L., Weinman K.M. 1996. How well protected are the forests of north-eastern New South Wales? - Analyses of forest environments in relation to formal protection measures, land tenure, and vulnerability to clearing. Forest Ecol. Manag. 85:311-33.

Reeves M.C., Winslow J.C., Running S.W. 2001. Mapping weekly rangeland vegetation productivity using MODIS algorithms. J. Range Manag. 54:90-105.

Rouse J.W., Haas R.H., Shell J.A., Deering D.W., Harlan J.C. 1974 Monitoring the vernal advancement of retrogradation of natural vegetation. Final Report, Type III, NASA/GSFC, Greenbelt, MD, USA.

Sabatini M., Verdiell A., Rodriguez Iglesias R.M., Vidal M. 2007. A quantitative method for zoning of protected areas and its spatial ecological implications. J. Environ. Manag. 83:198-206.

Saunders, D., Margules C., Hill B. 1998. Environmental indicators for national state of the environment reporting-biodiversity. Environment Australia, Department of the Environment. Available from: http://www.environment.gov.au/soe/publications/indicators/ pubs/biodiversity.pdf

Scott J.M., Davis F.W., McGhie G., Groves C. 2001. Nature reserves: do they capture the full range of Americ's biological diversity?. Ecol. Applicat. 11:999-1007.

Scotti M., Podani J., Jordan F. 2007. Weighting, scale dependance and in direct effects in ecological networks: a comparative study. Ecol. Complex. 4:148-59.

Secretariat of the Convention on Biological Diversity. 2005. Handbook of the convention on biological diversity including its cartagena protocol on biosafety. 3rd ed. Secretariat of the Convention on Biological Diversity, SCBD, Montreal, Canada.

Smirnov N.V. 1948. Tables for estimating the goodness of fit of empirical distributions. Annals Math. Stat. 19:279-96.

Stoll-Kleemann S. 2010. Evaluation of management effectiveness in protected areas: methodologies and results. Basic Appl. Ecol. 11:377-82.

Thackway R., Lee A., Donohue R., Keenan R.J., Wood M. 2007. Vegetation information for improved natural resource management in Australia. Landscape Urban Plan. 79:127-36.

Thompson M.E., Kahlenberg S.M., Gilby I.C., Wrangham R.W. 2007. Core area quality is associated with variance in reproductive success among female chimpanzees at Kibale National Park. Anim. Behav. 73:501-12.

Trodd N.M., Dougill A.J. 1998. Monitoring vegetation dynamics in semiarid African rangelands. Use and limitations of Earth observation data to characterize vegetation structure. Appl. Geogr. 18:315-30.

United Nations. 1992. Convention on biological diversity (CBD). Secretariat of CBD, Rio de Janeiro, Brazil. Available from: http://www. cbd.int/convention/text/

Verburg P.H., Overmars K.P., Huigen M.G.A., de Groot W.T., Veldkamp A. 2006. Analysis of the effects of land use change on protected areas in the Philippines. Appl. Geogr. 26:153-73.

Yapp G., Walker J., Thackway R. 2010. Linking vegetation type and condition to ecosystem goods and services. Ecol. Complex. 7:292-301.

Zerger A., Gibbons P., Seddon J., Briggs S., Freudenberger D. 2009, A method for predicting native vegetation condition at regional scales. Landscape Urban Plan. 91:65-77. 